Estudos da Língua(gem) - ISSN: 1982-0534

DOI: https://www.doi.org/ 10.22481/el.v19i4.9281

\title{
A variação entre as formas de pretérito imperfeito e futuro do pretérito para expressar eventos contrafactuais em língua portuguesa: um estudo sociofuncionalista
}

The variation between the forms of past imperfect tense and future of past tense to express counterfactual events in Portuguese: a sociofunctionalist study

La variación entre las formas de tiempo pasado y tiempo futuro para expresar eventos contrafácticos en portugués: un estudio sociofuncionalista

\section{Fábio Fernandes Torres}

Universidade da Integração Internacional da Lusofonia Afro-Brasileira (Unilab/Brasil) fabioftorres@unilab.edu.br

https://orcid.org/0000-0002-5972-5140

\section{Izabel Larissa Lucena Silva}

Universidade da Integração Internacional da Lusofonia Afro-Brasileira (Unilab/Brasil) izabel_larissa@unilab.edu.br https://orcid.org/0000-0001-5177-8267

\section{RESUMO}

Este artigo discute a variação entre as formas de pretérito imperfeito e futuro do pretérito em construções condicionais de natureza contrafactual, a partir dos dados de fala do português de Fortaleza, coletados por Torres (2009). O referencial teórico pressupõe o diálogo entre a Sociolinguística Variacionista e o Funcionalismo Linguístico, sob a configuração do Sociofuncionalismo, conforme Tavares (2003), Gorski; Tavares (2013), May (2009); Amorim; Sousa, (2019), entre outros. Os dados foram submetidos ao programa estatístico Goldvarb-X e analisados

* Sobre os autores ver páginas 84-85.

\begin{tabular}{|l|l|l|l|l}
\hline Estudos da Língua(gem) & Vitória da Conquista & v. 19, n. 4 & p. $59-85$ & dez. 2021 \\
\hline
\end{tabular}


a partir dos seguintes grupos de fatores extralinguísticos (idade, escolaridade e sexo) e linguísticos (complexidade estrutural, ordem, tipos de verbo, polaridade, fluxo de informação e modalidade). A análise estatística revela que a complexidade estrutural, a modalidade e o sexo são condicionadores do processo de variação entre o pretérito imperfeito e futuro do pretérito no contexto sintático-semântico da condicionalidade contrafactual.

PALAVRAS-CHAVE: Variação linguística; Sociofuncionalismo; Futuro do pretérito; Pretérito imperfeito; Língua portuguesa.

\section{ABSTRACT}

This paper discusses the variation between the forms of the past imperfect and the future of past in conditional constructions of a counterfactual nature, based on the speech data of the Portuguese of Fortaleza, collected by Torres (2009). The theoretical framework presupposes the dialogue between Variationist Sociolinguistics and Linguistic Functionalism, under the configuration of Sociofunctionalism, according to Tavares (2003), Gorski; Tavares (2013), May (2009); Amorim; Sousa, (2019), among others. The data were submitted to the Goldvarb-X statistical program and analyzed from the following groups of extralinguistic factors (age, education and sex) and linguistic factors (structural complexity, order, types of verb, polarity, information flow and modality). Statistical analysis reveals that structural complexity, modality and sex are conditioning factors in the process of variation between the past imperfect and the future of past in the syntactic-semantic context of counterfactual conditionality.

KEYWORDS: Linguistic variation; Sociofunctionalism; Past tense; Imperfect past tense; Portuguese language.

\section{RESUMÉN}

Este artículo analiza la variación entre las formas del pasado imperfecto y del futuro del pasado en construcciones condicionales de naturaleza contrafáctica, basadas en los datos del habla portuguesa de Fortaleza, recopilados por Torres (2009). El marco teórico presupone el diálogo entre Sociolingüística Variacionista y Funcionalismo Lingüistico, bajo la configuración del Sociofuncionalismo, segun Tavares (2003), Gorski; Tavares (2013), mayo (2009); Amorim; Sousa, (2019), entre otros. Los datos fueron sometidos al programa estadístico Goldvarb-X y analizados de los siguientes grupos de factores extralingüisticos (edad, educación y sexo) y lingüisticos (complejidad estructural, orden, tipos de verbos, polaridad, flujo de información y modalidad). El análisis estadístico revela que la complejidad estructural, la modalidad y el sexo son factores condicionantes en el proceso de variación entre el pasado imperfecto y el futuro del pasado en el contexto sintáctico-semántico de la condicionalidad contrafactual.

PALABRAS-CLAVE: Variación lingüistica; Sociofuncionalismo; Pasado; Pretérito imperfecto; Lengua portuguesa. 


\section{Introdução}

O foco central deste trabalho ${ }^{1}$ é analisar a variação entre as formas de pretérito imperfeito - PI e futuro do pretérito - FP em construções condicionais em Língua Portuguesa do seguinte tipo: uma oração hipotática (denominada, tradicionalmente, de oração adverbial), de natureza semântica condicional e contrafactual, e outra nuclear (ou oração principal, na nomenclatura tradicional). Objetivamos também verificar condicionamentos linguísticos e sociais que regulam o uso dessas variantes mediante análise estatística, pautada pelos princípios teóricos e metodológicos do Sociofuncionalismo.

Resumidamente, podemos destacar que a Sociolinguística Variacionista fornece o suporte teórico-metodológico para a compreensão e análise do fenômeno, com enfoque na não aleatoriedade variação entre formas linguísticas. Nesta perspectiva, a variação não se dá de forma livre, visto que a escolha de uma forma em detrimento de outra é influenciada por condicionadores de ordem linguística e extralinguística. O paradigma Funcionalista também preconiza uma relação não arbitrária entre a sistematicidade das formas linguísticas e a instrumentalidade do uso linguístico, compreendendo que é na interação comunicativa que as expressões linguísticas assumem seu valor funcional.

Dessa forma, a partir de uma abordagem que reconhece a possibilidade de diálogo na diferença (PIRES DE OLIVEIRA, 1999) entre a Sociolinguística e o Funcionalismo, o chamado Sociofuncionalismo, que se dedica aos estudos dos fenômenos de variação e mudança linguísticas e explica tais fenômenos por meio do "casamento teórico" (TAVARES, 2003) entre pressupostos teórico-metodológicos da Sociolinguística Variacionista e do Funcionalismo Linguístico, é que empreendemos o estudo da variação entre as formas pretérito imperfeito e futuro do pretérito no contexto sintático de oração adverbiais condicionais, procurando analisar, com o auxílio do programa estatístico Goldvarb-X, os seguintes condicionadores: extralinguísticos, tais como: a) idade, b) escolaridade e c) sexo; e linguísticos, a saber: a) complexidade estrutural, b) ordem estrutural da prótase, c) tipos de verbo, d) polaridade da construção condicional e) fluxo de informação e f) modalidade. No que concerne ao referencial teórico-metodológico, consideramos pressupostos da Sociolinguística Variacionista e do Funcionalismo Linguístico, sobretudo em relação às concepções de iconicidade e marcação de Givón (1991a, 1991b), sob a configuração teórica do Sociofuncionalismo proposto por Tavares (2003).

\footnotetext{
${ }^{1} \mathrm{O}$ artigo foi desenvolvido em conjunto pelos autores, como parte do projeto de pesquisa coordenado pelo professor Fábio Fernandes Torres, durante o período de 2019 a 2020, edital institucional da Pró-Reitoria de Pesquisa e Pós-Graduação da Universidade da Integração da Lusofonia Afro-Brasileira, Edital PROPPG $\mathrm{N}^{\circ} 03 / 2018$
} 
Em relação à organização retórica deste artigo, apresentamos, na seção 2, a seguir, os aspectos gerais que caracterizam a abordagem sociofuncionalista, subdividindo essa caracterização em subseções, que visam a fornecer um panorama dos postulados teóricos principais que orientam a análise do fenômeno em estudo. Em seguida, no item 3, discorremos sobre o pretérito imperfeito e futuro do pretérito, do ponto de vista dos estudos gramaticais tradicionais e dos estudos variacionais, caracterizando o contexto de variação da condicionalidade contrafactual. $\mathrm{Na}$ seção 4, apresentamos os procedimentos metodológicos que respaldam a análise dos dados, para, mais adiante, na seção 5, examinar o fenômeno à luz dos pressupostos assumidos. $\mathrm{Na}$ seção de conclusão, apresentamos as generalizações a que nos foram possíveis chegar, a partir da análise empírica dos dados. Ao final, listamos as referências consultadas no trabalho.

\section{Sociofuncionalismo}

A Sociolinguística Variacionista e o Funcionalismo Linguístico, principalmente a vertente norte-americana, têm sido aproximados constantemente na tentativa de melhor descrever os fenômenos linguísticos, havendo contribuições teóricas de um e outro modelo (PAIVA, 1998). Tavares (2003) empreendeu uma discussão em defesa de uma abordagem teórica resultante dessa aproximação com o objetivo de promover o casamento teórico entre os dois modelos, a que chamou de Sociofuncionalismo ${ }^{2}$. A proposta oferece uma interface teórica, de aspecto híbrido, que articula as duas vertentes teóricas distintas, que compartilham pressupostos convergentes (TAVARES, 2003, 2013; GORSKI; TAVARES, 2013, MAY, 2009; AMORIM; SOUSA, 2019, entre outros).

Por serem dois modelos de análise linguística bastante particulares, que deram suas contribuições com seus métodos e suas asserções acerca do fenômeno linguístico, é natural que esses dois paradigmas tenham postulados e peculiaridades que não podem ser aproximados e, portanto, não poderiam configurar em um modelo resultante, a partir do casamento das duas teorias ${ }^{3}$. Por outro lado, há entre os dois modelos teóricos uma série de similaridades de postulados teóricos, que poderiam ser complementares entre si, o que resultaria, a partir da convergência desses modelos, em um terceiro modelo teórico, responsável por dar suporte teórico a pesquisas que se lançam sobre as duas margens de um mesmo rio, como é o caso das pesquisas variacionistas

\footnotetext{
${ }^{2} \mathrm{O}$ termo Sociofuncionalismo ganhou destaque com as discussões travadas por Tavares (2003), contudo o termo surgiu ainda na década de 1990, nas pesquisas realizadas no Programa de Estudos sobre o Uso da Língua - PEUL/RJ, conforme Neves (1999). O grupo PEUL reúne pesquisadores que se dedicam ao estudo da variação e mudança linguística, na variedade falada e escrita do Português do Rio de Janeiro, adotando uma orientação essencialmente baseada na Sociolinguística Variacionista, dedicando-se à análise da língua em uso e sua inter-relação com aspectos sociais, estruturais e funcionais.

${ }^{3}$ Para uma discussão aprofundada sobre as convergências e divergências entre os dois modelos, ver Tavares (2003).
} 
que se vinculam ao Funcionalismo Linguístico para análise e interpretação dos dados.

Para Tavares (2003), é possível fazer uma associação de pressupostos teóricos vindos de fontes diferentes, desde que seja resultado de uma "conversa" travada em meio às diferenças. Contudo, não basta associar conceitos de fontes teóricas diferentes por parecerem "idênticos, semelhantes ou complementares" (TAVARES, 2003, p. 98) sem verificar se há de fato semelhanças e sem se decidir como lidar com as diferenças quando elas surgirem, já que nem todos os pressupostos de uma das teorias podem ser encaixados (ou incorporados pela) em outra. É preciso decidir o que será abarcado pelo Sociofuncionalismo e quais os aspectos de cada teoria devem ser abandonados e qual das teorias deve prevalecer na hora de tomar decisões sobre aspectos divergentes.

A análise entre compatibilidades e incompatibilidades entre propostas teóricas e metodológicas funcionalistas e variacionistas pressupõe a discussão do que vem a ser Sociofuncionalismo. Se é um "casamento" de teorias, disso decorrem duas possibilidades: (a) a teoria variacionista é estendida a ponto de incorporar pressupostos funcionalistas ou (b) são os estudos funcionalistas que incorporam a teoria variacionista (TAVARES, 2003). A autora propõe que a junção das duas teorias deve ocorrer como uma "conversa na diferença, pelo ajuste dinâmico, contextual e transitório entre conceitos e pressupostos teórico-metodológicos advindos de cada teoria "mãe" (TAVARES, 2003, p. 101). Assim, a cada reflexão e a cada estudo feito sob a égide do Sociofuncionalismo, o processo de associação de diretrizes teóricometodológicas adquire feições diferentes, advindas de experiências de adaptação e negociação durante a "conversa" de teorias. Nessa preocupação, os autores traduzem conceitos de uma teoria para a outra, "procurando chegar à convergência entre diferentes modos de ver" (TAVARES, 2003, p. 102).

Dentre os pressupostos convergentes, Tavares (2003) cita: (a) a prioridade atribuída à língua em uso; (b) os fenômenos linguísticos investigados são analisados em situações de comunicação real de sujeitos reais interagindo; (c) a concepção de que a língua está sempre mudando; (d) a mudança linguística é entendida como lenta, contínua e gradual; (e) a mudança é observável nos âmbitos linguístico e social; (f) a mudança pode ser observada a partir de dados sincrônicos e diacrônicos; (g) o princípio do uniformitarismo, segundo o qual as forças linguísticas e sociais que agem na língua provocando variação e mudança são as mesmas de épocas passadas; (h) análise de aspectos fonológicos, morfológicos, sintáticos e semânticos na língua; (i) atenção dada à frequência; (j) a afirmação de que há relação entre os fenômenos linguísticos e a sociedade em que ocorrem.

Dentre as diferenças apontadas por Tavares (2003), destaca-se a concepção de gramática como um processo em andamento, sempre em constituição, resultado de pressões de cada ato de comunicação de seus falantes - pelo funcionalismo givoniano; e como um sistema de regras 
variáveis, para a sociolinguística variacionista. Assim, o Funcionalismo atribui um papel central à função, dado que se uma forma linguística é utilizada devese a uma razão funcional. A Sociolinguística atribui uma importância à estrutura variável, parte da competência dos falantes. Sob esse aspecto, as duas teorias são divergentes. As regras variáveis para a Sociolinguística "representam um modo de descrever formalmente a inter-relação sistemática entre condicionamentos internos e externos à língua" (TAVARES, 2003, p. 121). O funcionalismo givoniano, baseado na concepção de gramática emergente, está interessado nas relações que se estabelecem, em diferentes graus, entre "funções e formas e a alteração por que passam tais relações ao longo do tempo, não se ocupando em estipular regras abstratas subjacentes ao uso" (TAVARES, 2003, p. 121). Para o funcionalismo,

o alvo não é a descrição da estrutura variável da língua e das regras que a governam em uma dada fatia de tempo, mas sim a análise das tendências de uso manifestadas pelos falantes - tendências que se traduzem em forma de frequências reveladoras de maior ou menor rotinização (TAVARES, 2003, p. 121).

Essa "conversa na diferença”" entre os pressupostos das duas teorias requer que o quadro teórico resultante apresente aspectos comuns, semelhantes ou complementares a ponto de permitir a convergência de pressupostos das duas teorias, mas o foco de cada teoria é diferente, mais que isso, segundo Tavares, há diferenças que são inconciliáveis, e o pesquisador deverá tomar decisões:

(i) ou a primazia da análise recai sobre a função ou sobre a estrutura; (ii) ou as motivações por trás da gramática podem ser funcionais ou não podem; (iii) ou a gramática é o conjunto de regularidades que emergem das pressões de uso cotidianas ou a gramática é o conjunto de regras (in)variáveis formais que governam o uso gramatical a cada período de tempo (TAVARES, 2003, p. 132).

A abordagem sociofuncionalista será possível, dessa forma, sempre que o pesquisador estabelecer as convergências e as divergências entre as duas teorias e que pressupostos puderem ser ajustados, negociados a ponto de permitir o surgimento de matizes teóricos diferenciados dos modelos fonte. Isso exige do pesquisador um posicionamento claro, já que ele não é um mero mediador de conceitos a serem emparelhados. Dessa forma, passemos a discutir alguns conceitos que são importantes para esta pesquisa, definindo como eles serão interpretados. 


\subsection{O princípio da iconicidade e da marcação}

Givón (1992) define iconicidade como um princípio linguísticopragmático ligado à relação motivada entre forma e função. Para esse autor, a iconicidade nas línguas pode manifestar-se a partir de três subprincípios de organização morfossintática: (i) subprincípio da quantidade, (ii) subprincípio da proximidade ou integração e (iii) subprincípio da ordenação sequencial ou linear.

O subprincípio da quantidade prevê que blocos de maior informação e menos previsíveis ou mais relevantes do ponto de vista comunicativo recebam maior codificação morfossintática. Tal subprincípio se reflete, por exemplo, no tamanho das palavras derivadas em comparação com as não derivadas, tal como em: "act > act-ive > act-iv-ate > act-iv-at-ion" (GIVÓN, 1992, p. 03). Assim, quanto maior a quantidade de codificação morfossintática mais complexo é o conceito que a palavra expressa.

O subprincípio da proximidade explica que entidades, funcional e cognitivamente mais próximas, aparecerem integradas, temporal e espacialmente, no plano da codificação morfossintática; além de postular que operadores funcionais tendem a ser codificados próximos, temporal e espacialmente, das unidades para as quais são relevantes. Esse subprincípio, segundo Givón (1992), se reflete no grau de integração de cláusulas com função de complemento em relação à sua oração matriz, tal como em: "She said: 'He's gone' $>$ She forgot that he had gone $>$ She wished that he would go $>$ She wanted him to go > She let him go > She let-go of him" (GIVÓN, 1992, p. 05).

O subprincípio da ordenação sequencial pode estabelecer-se, conforme o linguista, de duas maneiras: (i) na ordenação dos eventos na cláusula que tendem a aparecer na ordem temporal em que ocorreram e (ii) na ordem de importância ou relevância que certas porções de informação apresentam quando postas em primeiro lugar na cadeia sintática. Esse subprincípio, de acordo com Givón, manifesta-se, por exemplo, em enunciados cuja ordem dos eventos na oração não pode ser alterada, como em: "He opened the door, came in, sat and ate" / *He sat, came in, ate and opened the door" (GIVÓN, 1992, p. 08).

O princípio de marcação, para Givón (1990), constitui um imperativo meta-icônico, já que diz respeito à relação motivada entre complexidade estrutural e complexidade cognitiva ou comunicativa. Como construto teórico, a marcação pressupõe a oposição entre dois subconceitos, que se opõem: marcado e não marcado. Segundo Givón (1990), tal distinção entre estruturas marcadas e não marcadas tem relação com três critérios ou subprincípios interdependentes:

(i) complexidade estrutural - a estrutura marcada tende a ser mais complexa (ou maior) do que a correspondente não marcada; 
(ii) distribuição de frequência - a categoria marcada tende a ser menos frequente, portanto, cognitivamente mais saliente do que a categoria não marcada correspondente;

(iii) complexidade cognitiva - a categoria marcada tende a ser cognitivamente mais complexa, tanto em termos de esforço mental, demandas de atenção quanto em termos de processamento cognitivo do que a categoria não marcada.

Para o autor, a tendência geral das línguas é que esses critérios coincidam, ou seja, que haja uma associação entre marcação estrutural, marcação cognitiva e baixa frequência de uso, o que corresponderia a uma propriedade geral de iconicidade na gramática das línguas naturais. Ressaltamos, por outro lado, que Givón esclarece que a marcação que caracteriza uma forma linguística é relativa, pois uma construção pode ser marcada num dado contexto e não marcada em outro. Para ilustrar isso, Givón explica, por exemplo, que a oração ativa é não marcada na comunicação oral informal; por outro lado, a passiva é não marcada no discurso acadêmico, que é marcado em relação à comunicação cotidiana. Esses correlatos cognitivos, comunicativos e socioculturais variam de um domínio para o outro, uma vez que as estruturas biológicas são adaptativamente motivadas.

\subsection{Polaridade, modalidade e fluxo de informação}

A polaridade diz respeito à escolha entre os polos positivo e negativo na oração. Em língua portuguesa, o polo positivo não requer expressão formal explícita, ao passo que o polo negativo se manifesta por meio de um elemento formal autônomo ou pela repetição de mais de um elemento de negação, a chamada dupla negação. Para Halliday (1989), a polaridade é, tipicamente, expressa na oração por meio do elemento finito, que pode ter como meios de expressão formas positivas (é, foi, está, tem, pode) ou negativas (não é, não foi, não está, não tem, não pode).

Neves (2006, p. 210) esclarece que a afirmação, quando explicitada, pode estar atrelada a um ponto de vista semântico-discursivo de redundância. Além disso, o emprego de marca de polaridade afirmativa ou negativa pode indicar uma função textual-discursiva de referência "fórica" afirmativa ou negativa, ligada a uma oração interrogativa. A autora argumenta, ainda, que a afirmação e a negação podem indicar concordância ou discordância em relação a um enunciado, extrapolando, dessa forma, a pura função de polaridade.

$\mathrm{Na}$ Gramática Sistêmico-Funcional (1985), o terreno das opiniões e das reações se situam em níveis intermediários entre os polos negativo e positivo, o que significa reconhecer a modalidade como um terreno que se relaciona com a polaridade. Dessa forma, Halliday reconhece que uma escolha para uma resposta pode se situar em graus intermediários entre sim e não. Segundo Halliday (2004), um "talvez", que tem relação com graus de 
comprometimento do falante (possivelmente $>$ provavelmente $>$ com certeza), e um "às vezes”, que se associa com graus de habilidade (às vezes > comumente $>$ sempre), marcam graus intermediários de polaridade e modalidade, tanto em relação a um ponto de vista qualitativo ("talvez") como quanto a um ponto de vista quantitativo ("às vezes").

Esse autor vê a modalidade como um recurso léxico-gramatical ligado à metafunção interpessoal para a manifestação de significados intersubjetivos relacionados às opiniões e aos julgamentos do falante em diferentes níveis ou graus. Assim, a modalidade diz respeito à distinção entre proposição (troca de informações) e propostas (troca de bens e serviços), subdivididas, respectivamente, em: (i) modalização e (ii) modulação.

A modalidade, também denominada de modalidade epistêmica, se aplica às proposições e pode expressar graus de probabilidade ou usualidade das informações. Esses significados epistêmicos podem manifestar-se por diferentes meios linguísticos, tais como: verbos modais (poder e dever), adjuntos modais (possivelmente, talvez, certamente, frequentemente etc), grupos adverbiais (sem dúvidas, com certeza, às vezes) e adjetivos em função predicativa (é possível, é provável, é certo, é corriqueiro etc).

A modulação, também chamada de modalidade deôntica, diz respeito a propostas (comandos e ofertas). No caso da função semântica comando, os graus de obrigação são: permitido, aceitável, necessário, obrigatório. No caso da função semântica oferta, os graus de inclinação são: inclinado, desejoso, disposto, determinado. Tanto a obrigação quanto a inclinação manifestam-se por meios linguísticos diversos, como verbos modalizadores (dever, deveria), adjuntos modais (necessariamente, obrigatoriamente, alegremente etc) e adjetivos em função predicativa (é necessário, é esperado, está disposto a etc).

No que diz respeito à noção de fluxo de informação, essa noção tem relação com o princípio de informatividade da oração, ou seja, ao reconhecimento de que a oração constitui uma unidade não apenas estrutural, mas também uma unidade informacional, comunicativa. Sob esse ponto de vista, reconhece-se que a oração apresenta uma informação dada, amplamente compartilhada pelos interlocutores, e informação nova, que constitui o objetivo da interação. Nesta pesquisa, os grupos de fatores linguísticos foram elencados a partir desses conceitos.

\section{0 pretérito imperfeito e o futuro do pretérito na expressão de contrafactualidade}

Segundo Brito (2014), a contrafactualidade é um fenômeno pouco estudado nos estudos da linguagem. A autora dedica-se ao estudo da contracfatualidade que se expressa na oração principal, canonicamente, pela forma verbal de futuro do pretérito, mas que varia, nesse contexto, com a forma verbal de pretérito imperfeito do indicativo. Segundo Neves (2000), no bojo das construções condicionais em Língua Portuguesa, que se caracterizam 
por expressar relações lógico-semânticas do tipo "se p, então q", em que p (oração 1) estabelece as condições de realização de q (oração 2), sendo "a oração que exprime a condição (tradicionalmente, a subordinada) chamada de prótase e a que exprime o que é condicionado (a nuclear, ou principal) chamada de apódose" (NEVES, 2000, p. 832). Para a autora, esse tipo de relação que se instaura entre o conteúdo da oração condicionante e da oração condicionada se resolve, nesta última, do seguinte modo: a) realização/fato (factualidade); b) não realização/não fato (ou contrafactualidade); realização eventual/fato eventual (eventualidade).

É no cerne dessas relações, em que um fato futuro (futuro do pretérito) depende que certas condições no passado (pretérito imperfeito do subjuntivo) sejam satisfeitas para ocorrer, em que se estabelece o contexto de variação entre futuro do pretérito e pretérito imperfeito, a que se dedica esta pesquisa. Brito (2018) compreende a contrafactualidade e a condicionalidade como macrodomínios funcionais, que englobam, como um de seus microdomínios, a condição contrafactual, de modo que a condição contrafactual se constitui como microdomínio que se configura na intersecção de dois domínios mais amplos, o da contrafactualidade e o da condicionalidade. No que diz respeito ao emprego do futuro do pretérito, as gramáticas tradicionais indicam que esse tempo verbal é usado para expressar "um fato que se dará, agora ou no futuro, dependendo de certa condição" (BECHARA, 2003, p. 280), ou ainda, "nas afirmações condicionadas, quando se referem a fatos que não se realizaram e que, provavelmente, não se realizarão" (CUNHA; CINTRA, 2017, p. 477). A expressão dessa função, contudo, ocorre de modo variável por meio das formas de futuro do pretérito e pretérito imperfeito, como em (1) a seguir, em que o imperfeito, em forma perifrástica, é empregado com a função de futuro do pretérito.

(1) “...Se eu fosse candidata... eu ia lutar muito por três coisa eu ia lutar pela saúde..." 4

Segundo Bechara (2003), empregamos o pretérito imperfeito quando nos transportarmos mentalmente a uma época passada e a descrevemos o que então era presente, e pode ser empregado no lugar do futuro do pretérito "para denotar um fato certo como consequência de outro que não se deu": "Eu, se tivesse crédito na praça, pedia outro empréstimo” (Bechara, 2003, p. 278). Cunha; Cintra (2017), ao referir-se ao emprego do pretérito imperfeito, aproximam-se da definição de Bechara (2003). O pretérito imperfeito, conforme os gramáticos, assume um lugar de futuro do pretérito "para denotar um fato que seria consequência certa e imediata de outro, que não ocorreu, ou

${ }^{4}$ Extraído do corpus coletado por XXX (2009). 
não poderia ocorrer", a exemplo de: "Se eu não fosse mulher, ia também" (CUNHA; CINTRA, 2017, p. 466).

A variação entre pretérito imperfeito e futuro do pretérito em língua portuguesa tem despertado o interesse dos estudos variacionistas, tendo sido foco de investigação de Brito (2014, 2018); Barbosa (2005); Oliveira (2010); Dias (2007, 2012); Freitag; Araújo (2011) entre outros. Dias (2007) afirma que os falantes, conscientes das diferentes formas gramaticais disponíveis nas línguas, criam diversas possibilidades de representações modo-temporais nas orações nucleares, de mesmo valor referencial, como podemos observar nos exemplos postos pela a autora: "Se eu quisesse tomar banho, não teria dado tempo"; "Se eu quisesse tomar banho, não tinha dado tempo"; "Se eu quisesse tomar banho, não daria tempo"; "Se eu quisesse tomar banho, não dava tempo".

Barbosa (2005) aponta para uma preferência de uso do futuro do pretérito em relação ao pretérito imperfeito em orações condicionais em dados de fala de Uberlândia (MG), com percentuais de 55,7\% e 44,3\% respectivamente. Os dados de sua pesquisa revelaram que os informantes de classe baixa e de faixa etária acima de 45 anos usam, com mais frequência, o pretérito imperfeito e que as duas formas são mais frequentes na ordem canônica da sentença. Freitag; Araújo (2011) afirmam que o futuro do pretérito é polissêmico, já que expressa valores relacionados ao domínio do tempo (futuro do passado) e da modalidade (polidez e condicionalidade) e que a condicionalidade pode ser expressa por mais de uma forma verbal no português: forma de futuro do pretérito - FP -, as formas de pretérito imperfeito - IMP - e as formas perifrásticas emergentes - IA+V e IRIA+V que também podem expressar este valor semântico-discursivo (FREITAG; ARAÚJO, 2011, p. 201). A pesquisa de Freitag; Araújo (2011), com dados de fala de universitários de Itabaiana/SE, revela que a forma canônica - futuro do pretérito - é a mais recorrente na amostra analisada (70\% de frequência) e é favorecida pelo paralelismo formal, tanto em ocorrência isolada quanto em contexto de passado condicional precedido de futuro do pretérito; pela ordem canônica (prótase +apódose); por verbos semânticos de atividade; por contextos discursivos opinativos e explicativos.

Oliveira (2010) também se dedicou à alternância entre essas formas verbais, em corpus constituído pelo pesquisador, composto por 48 entrevistas sociolinguísticas de fala de Alagoas, estratificadas por sexo, idade e escolaridade. Os resultados estatísticos apontaram como relevantes os grupos de fatores ordem da sentença, escolaridade, sexo, idade. Os dados totais apontam maior frequência de uso do futuro do pretérito (61\%) em detrimento ao pretérito imperfeito (41\%), contudo essa frequência é ainda maior quando considerada a escolaridade dos informantes: $66 \%$ para futuro do pretérito e $34 \%$ para o pretérito imperfeito entre informantes com curso superior. A ordem canônica da sentença favorece o pretérito imperfeito, diferenciando-se dos resultados encontrados por Barbosa (2005). Os informantes da segunda 
faixa etária (31- 45 anos) usam mais o futuro do pretérito (67\%), enquanto nas outras faixas-etárias, a distribuição das variantes mostrou-se bem aproximada. Os resultados também apontam uma tendência maior de uso do pretérito imperfeito pelo sexo masculino, enquanto o sexo feminino favorece o uso da forma canônica de futuro do pretérito.

Os resultados da pesquisa de Brito (2018) mostram que: a) o uso de futuro do pretérito (simples ou composto) prevalece sobre o uso de pretérito imperfeito (simples ou composto) no contexto geral de uso, sendo as formas simples as mais recorrentes; b) o pretérito imperfeito (simples e composto) é favorecido pelos falantes mais jovens (entre 20-30 anos); c) o futuro do pretérito (simples e composto) é mais frequente na escrita de indivíduos do sexo masculino e o pretérito imperfeito (simples e composto) destaca-se na escrita de indivíduos do sexo feminino; d) a ordem estrutural das orações e a estruturação da prótase não foram significativas para a alternância entre futuro do pretérito e pretérito imperfeito; e) a postura subjetiva do escrevente foi selecionada a mais relevante para ambas as variáveis: futuro do pretérito (simples e composto) é favorecido em contextos de postura negativa, ao passo que o pretérito imperfeito (simples e composto) predomina em contextos de postura positiva; entre outros. Segundo a autora, os resultados referentes aos fatores sociais idade e sexo apontam para a possibilidade de mudança em progresso liderada por mulheres na direção do aumento de uso de pretérito imperfeito; enquanto os resultados referentes à escolaridade mostram que o futuro do pretérito, a forma prestigiada, é favorecido por aqueles têm ensino superior e pretérito imperfeito por aqueles com ensino fundamental e médio.

\section{Metodologia da pesquisa}

O corpus desta pesquisa foi coletado por Torres (2009), ao longo de 2008 e início de 2009, por meio de entrevistas sociolinguísticas, metodologicamente organizado para flagrar a variação entre as formas de expressão de tempo futuro, mediante a seleção, prévia, de alguns tópicos para orientar as entrevistas. Para este trabalho, foram selecionadas 40 entrevistas, estratificadas a partir dos seguintes grupos de fatores sociais: idade (20 a 30 anos e acima de 40 anos); escolaridade (ensino médio e ensino superior); sexo (masculino e feminino). Como a variável tem relevância no nível sintáticosemântico, também consideramos os seguintes grupos de fatores linguísticos: complexidade estrutural (formas simples e formas perifrásticas); (b) ordem estrutural da prótase (construção condicional na ordem canônica: prótase + apódose; construção condicional em ordem inversa: apódose + prótase), conforme Costa (2003), Barbosa (2005), Freitag; Araújo (2011) Brito (2018), entre outros; (c) polaridade da construção condicional (afirmativa ou negativa); (d) fluxo de informação (dado e novo); (e) modalidade (epistêmica e deôntica). 
Diferentemente de Brito (2018), que testou separadamente a variação entre as formas simples (variável 1) e compostas (variável 2) do futuro do pretérito e pretérito imperfeito, nesta pesquisa, controlamos a complexidade estrutural das formas como grupo de fatores e tratamos a variação de forma binária.

Os dados coletados foram codificados e submetidos à análise estatística do programa GoldVarb X (SANKOFF; TAGLIAMONTE; SMITH, 2005), que testa a influência dos grupos de fatores controlados na pesquisa sobre a ocorrência de uma e outra variante, selecionando, dentre esses grupos de fatores, aqueles que apresentaram relevância estatística. Os resultados decorrentes da análise estatística foram interpretados à luz da Teoria Variacionista e do Funcionalismo Linguístico, sob a configuração do Sociofuncionalismo.

\section{Resultados e discussões da pesquisa}

Partindo do pressuposto de que o emprego do futuro do pretérito ou do pretérito imperfeito para expressar a contrafactualidade não está sujeita a variação livre, mas obedece a condicionamentos de natureza social e linguística, os dados foram codificados e submetidos a tratamento estatístico no programa Goldvarb-X para verificar a influência de fatores sociais (faixaetária, sexo, escolaridade) e os fatores linguísticos (complexidade estrutural, modalidade, ordem da conjunção, tipo de verbo, polaridade, fluxo de informação). Foram encontradas 113 ocorrências das variantes estudadas, sendo 76 ocorrências de futuro do pretérito, o que corresponde a uma frequência de $67,3 \%$ e 37 ocorrências de pretérito imperfeito do indicativo, cuja frequência equivale a $32,7 \%$, conforme os dados da tabela 01 .

Tabela 01: resultado geral das ocorrências das variantes

\begin{tabular}{l|l}
\hline \multicolumn{2}{c}{ Resultado geral } \\
\hline Futuro do pretérito & Pretérito imperfeito \\
\hline $\mathbf{n}^{\mathbf{0}}$ de ocor./perc. & $\mathbf{n}^{\mathbf{0}}$ de ocor./perc. \\
\hline $76 / 67,3 \%$ & $37 /$ \\
\hline
\end{tabular}

Fonte: elaborada pelos pesquisadores.

A partir destes dados, podemos constatar que, no contexto desta pesquisa, com dados de fala de informantes de Fortaleza, o futuro do pretérito é a forma preferida para se referir a eventos contrafactuais ou hipotéticos, alinhando-se aos resultados de Oliveira (2010), Freitag; Araújo (2011); Brito (2014, 2018), Barbosa (2005). O GoldvarbX selecionou, como estatisticamente relevantes, os seguintes grupos de fatores: complexidade 
estrutural, modalidade e sexo, nesta ordem, cujos resultados serão discutidos na mesma ordem de relevância.

\section{a) complexidade estrutural}

Nossa hipótese era que o imperfeito do indicativo teria uma frequência maior de ocorrências em formas verbais perifrásticas, hipótese também aventada por Dias (2007), por ser a forma inovadora, a semelhança do que ocorre com a variação das formas de futuro do presente, em que a forma perifrástica é a mais frequente; e que o futuro do pretérito seria mais frequente em formas verbais simples, por ser a forma canônica para esta função. Historicamente, a inserção da perífrase foi muito importante na formação dos tempos verbais em língua portuguesa, como aponta Câmara Jr (1975). Os resultados mostram que a forma simples favorece o uso de futuro do pretérito, com peso relativo de 0,708 , e a forma verbal perifrástica favorece a variante pretérito imperfeito do indicativo, com um peso relativo de 0,769 , conforme os dados da tabela abaixo:

Tabela 02: atuação do grupo de fatores complexidade estrutural

\begin{tabular}{l|l|l}
\hline \multicolumn{1}{c|}{ Variantes } & \multicolumn{1}{|c}{ Futuro do pretérito } & \multicolumn{1}{c}{ Pretérito imperfeito } \\
\hline $\begin{array}{l}\text { Complexidade } \\
\text { estrutural }\end{array}$ & $\begin{array}{l}\left(\mathbf{n}^{\mathbf{0}} \text { de ocor./total)/ perc./peso }\right. \\
\text { relativo }\end{array}$ & $\begin{array}{l}\left(\mathbf{n}^{\mathbf{0}} \text { de ocor./total)/ }\right. \\
\text { perc./peso relativo }\end{array}$ \\
\hline Simples & $(53 / 65) / 81,5 \% / \mathbf{0 , 7 0 8}$ & $(12 / 65) / 18,5 \% / 0,292$ \\
\hline Perifrástica & $(23 / 48) / 47,9 \% / 0,231$ & $(25 / 48) / 52,1 \% / \mathbf{0 , 7 6 9}$ \\
\hline
\end{tabular}

Fonte: elaborada pelos pesquisadores.

A ocorrência (2) e (3) exemplificam o uso de uma e outra variante, sob a influência dos fatores relevantes para esse grupo.

(2) Se as empresas recebessem incentivo com certeza haveria muita vaga mesmo pro pessoal do primeiro emprego.

(3) se eu fosse político eu ia fazer isso visitar mesmo pra ver isso tudo concretizado se tá funcionando mesmo e não ocorre.

$\mathrm{Na}$ perspectiva givoniana, o princípio da marcação postula que determinada estrutura linguística tende a ser marcada em uma situação e não marcada em outra situação diversa, conforme os critérios de complexidade estrutural, de distribuição de frequência e de complexidade cognitiva. Givón (1991) afirma que a estrutura marcada tende a ser mais complexa do que a nãomarcada, mas isso está relacionado ao contexto comunicativo, social, cultural e cognitivo. Considerando, assim, a correlação entre esses três critérios de marcação, podemos afirmar que o pretérito imperfeito constitui a forma 
marcada no contexto da oração condicional contrafactual. Por outro lado, uma análise mais atenta dos dados nos mostra que a forma perifrástica do pretérito imperfeito, na expressão do microdomínio da contrafactualidade, revela-se como a forma preferida, em oposição à forma simples de futuro do pretérito, como forma canônica, não marcada, de manifestação de significados contrafactuais, o que pode ter relação com o princípio givoniano da iconidade.

Pelo princípio givoniano da iconidade, que prevê forte correlação entre forma e função, os resultados parecem confirmar o subprincípio da quantidade, que prevê uma forte correlação entre quantidade de informação e sua codificação na estrutura linguística. Assim, a maior frequência de imperfeito perifrástico no contexto da contrafactualidade pode estar associada ao fato de essa estrutura gramatical expressar, por meio da perífrase verbal com o verbo ir no imperfeito, a função de futuro do pretérito, diferenciandose, dessa forma, da função de passado. A perífrase com ir parece remeter mais diretamente ao futuro (do pretérito) que a forma simples do imperfeito.

\section{b) modalidade}

Os dados mostram que a modalidade deôntica favorece o uso do futuro do pretérito, com uma frequência de $90 \%$ e peso relativo de 0,915 . A modalidade epistêmica não parece favorecer nenhuma das variantes, quando consideramos os pesos relativos muito próximos ao padrão considerado neutro, conforme os dados da tabela 3, embora se perceba maior frequência de uso do futuro do pretérito que do pretérito imperfeito associado a essa modalidade.

Tabela 03: atuação do grupo de fatores modalidade

\begin{tabular}{|c|c|c|}
\hline Variantes & Futuro do pretérito & Pretérito imperfeito \\
\hline Modalidade & $\begin{array}{l}\left(\mathrm{n}^{\circ} \text { de ocor./total)/ }\right. \\
\text { perc./peso relativo }\end{array}$ & $\begin{array}{l}\text { ( } \mathrm{n}^{\circ} \text { de ocor./total)/ } \\
\text { perc./peso relativo }\end{array}$ \\
\hline Deôntica & $(9 / 10) / 90 \% / \mathbf{0 , 9 1 5}$ & $(1 / 10) 10 \% / 0,085$ \\
\hline Epistêmica & $(67 / 103) / 65 \% / 0,443$ & $(36 / 103) / 35 \% / \mathbf{0 , 5 5 7}$ \\
\hline
\end{tabular}

Fonte: elaborada pelos pesquisadores.

De modo geral, podemos definir a modalidade como a expressão da atitude subjetiva do falante, que "assume com maior ou menor força o que enuncia, ora comprometendo-se, ora afastando-se, seguindo normas determinadas pela comunidade em que se insere" (CORACINI, 1991, p. 113). No que diz respeito aos significados modais, podemos, conforme Halliday (1985), subdividir os recursos interpessoais de expressão da modalidade em dois subtipos principais: a modalidade epistêmica e a modalidade deôntica.

Por significados epistêmicos, entendemos os recursos linguísticos (lexicais e gramaticais) de manifestação de graus de probabilidade (certo, 
provável, possível) ou usualidade (sempre, usualmente, às vezes). Além disso, a modalidade epistêmica tem relação com os graus de comprometimento (alto, médio e baixo) do falante no que diz respeito aos julgamentos e às opiniões que manifesta.

Por significados deônticos, compreendemos os meios de expressão (lexicais e gramaticais) relativos aos graus de obrigação (permitido, aceitável, necessário, obrigatório) e de inclinação (inclinado, desejoso, disposto, determinado). De acordo com Menezes (2011), a modalidade deôntica "diz respeito ao que é legal, moral, socialmente admitido" (MENEZES, 2011. p. 118), caracterizando-se por sua relação intrínseca com a futuridade, uma vez que "obrigações" dizem respeito a estados de mundos a serem obtidos caso a obrigação imposta seja levado a termo. Por essa razão, postulamos a hipótese de que a modalidade deôntica ocorreria, com mais frequência, em sentenças com o futuro do pretérito.

As ocorrências (4) e (5), a seguir, ilustram construções modais na forma de futuro do pretérito:

(4) Se uma pessoa entra quando a pessoa entra em uma profissão principalmente essa de servir a sociedade deveria se conscientizar alguma coisa assim do tipo para combater fazer eles mesmo fazerem algumas coisas que pudessem diminuir alguma coisa que tipo.

(5) Eu acho que assim se a pessoa se fosse policial ela teria que servir a sociedade ele teria que combater os ladrões e não se aliciar ele alguma coisa tipo porque isso acontece muito.

$\mathrm{Na}$ ocorrência (4), a obrigação interna, ditada pela consciência, é expressa por meio de um verbo auxiliar modal (“dever") no futuro do pretérito simples. Na ocorrência (5), a obrigação externa, ditada por circunstâncias externas (o papel do policial na sociedade), tem base numa necessidade alética, expressa por meio de um predicado ("ter que"), que envolve o traço [+controle]. Nesses contextos, evidenciais em (4) e (5), observamos que os significados de obrigação são mitigados pelo uso do futuro do pretérito.

\section{c) $\operatorname{sexo}$}

Nossa hipótese para esse grupo de fatores leva em conta a concepção clássica de que as mulheres favorecem a forma de prestígio (PAIVA, 2010). Por considerarmos o futuro do pretérito a forma de prestígio e conservadora, já que é a forma canônica nessa função, era esperado maior frequência de uso associado ao sexo feminino. Os resultados confirmam essa hipótese, uma vez que a frequência do uso de futuro do pretérito na fala das mulheres é 75,5\% e peso relativo foi de 0,634. Já na fala de informantes homens, a frequência de uso para essa variante é $60,9 \%$ e peso relativo de 0,396 . Por outro lado, o 
pretérito imperfeito é favorecido pelo uso de informantes do sexo masculino, ainda que haja maior frequência de uso de futuro do pretérito para ambos os sexos. Vejamos os dados da tabela a seguir:

Tabela 04: atuação do grupo de fatores sexo do informante

\begin{tabular}{l|l|l}
\hline Variantes & Futuro do pretérito & \multicolumn{1}{c}{ Pretérito imperfeito } \\
\hline Sexo & $\begin{array}{l}\left(\mathbf{n}^{\mathbf{0}} \text { de ocor./total)/ perc./peso }\right. \\
\text { relativo }\end{array}$ & $\begin{array}{l}\left(\mathbf{n}^{\mathbf{0}} \text { de ocor./total)/ }\right. \\
\text { perc./peso relativo }\end{array}$ \\
\hline Feminino & $(37 / 49) / 75,5 \% / \mathbf{0 , 6 3 4}$ & $(12 / 49) / 24,5 \% / 0,366$ \\
\hline Masculino & $(39 / 64) / 60,9 \% / 0,396$ & $(25 / 64) / 39,1 \% / \mathbf{0 , 6 0 4}$ \\
\hline
\end{tabular}

Fonte: elaborada pelos pesquisadores.

Esses resultados confirmam a tendência das pesquisas sociolinguísticas, quando se observa o encaixamento da variável em relação ao sexo do informante. As mulheres tendem a reter a forma mais prestigiada, tendência que se observa em outros fenômenos variáveis, quando uma das formas é estigmatizada ou que tem uso não previsto na gramática normativa. Esses resultados assemelham-se aos encontrados por Oliveira (2010), cuja pesquisa aponta para uma preferência de uso do futuro do pretérito por mulheres e homens, com percentuais $65 \%$ e $45 \%$, e que o futuro do pretérito é condicionado pelas mulheres, com peso relativo de 0,56 , ao passo que o pretérito imperfeito é condicionado pelos homens, com peso relativo também de 0,56 .

Considerada a discussão em torno dos grupos de fatores selecionados como estatisticamente relevantes, discutiremos, agora, os resultados percentuais referentes aos outros grupos de fatores, a começar pelos grupos de fatores sociais e, em seguida, os grupos de fatores linguísticos.

\section{d) idade}

Quando se considera a idade do falante, os dados revelam que o futuro do pretérito e o pretérito imperfeito têm distribuição de frequência bastante semelhante, com dados percentuais muito próximos, ainda que se observe frequência um pouco superior para o futuro do pretérito na primeira faixa-etária. Nossa hipótese inicial era que a ocorrência do pretérito imperfeito na função de futuro do pretérito seria mais frequente na faixa-etária mais jovem, por ser considerada uma variante inovadora.Vejamos os dados na tabela 5 . 
Tabela 05: atuação do grupo de fatores idade do informante

\begin{tabular}{l|l|l}
\hline Variantes & Futuro do pretérito & Pretérito imperfeito \\
\hline Idade & $\left(\mathbf{n}^{\mathbf{0}}\right.$ de ocor./total $) /$ perc. & $\left(\mathbf{n}^{\mathbf{0}}\right.$ de ocor./total $) /$ perc. \\
\hline $\mathbf{2 0}$ a $\mathbf{3 0}$ anos & $(38 / 54) / 70,4 \%$ & $(16 / 54) / 29,6 \%$ \\
\hline Acima de $\mathbf{4 0}$ anos & $(38 / 59) / 64,4 \%$ & $(21 / 59) 35,6 \%$ \\
\hline
\end{tabular}

Fonte: elaborada pelos pesquisadores.

Os resultados mostraram que, de modo semelhante ao que se observou no uso das variantes em relação ao sexo dos informantes, o futuro do pretérito é a forma preferidas pelos dois grupos etários considerados na pesquisa, com percentuais $70,4 \%$ e $64,4 \%$, respectivamente para o primeiro e segundo grupo. Esse grupo foi testado por Oliveira (2010) em três faixas etárias (15 - 30 anos; 31-45 anos; 46-60 anos), cujas frequências de uso do futuro do pretérito foram $56 \%, 67 \%$ e $55 \%$. Contudo, este grupo de fator apresentou relevância estatística da segunda faixa etária como condicionadora do futuro do pretérito e as outras faixas etárias como favorecedoras do pretérito imperfeito.

\section{e) escolaridade}

No que diz respeito ao fator escolaridade, a nossa hipótese era que falantes com ensino superior favoreceriam o uso do futuro do pretérito, que seria a variante conservadora, aquela prevista pela gramática normativa, e falantes com escolaridade de ensino médio favoreceriam a variante pretérito imperfeito, a forma inovadora. Contudo, a distribuição das variantes, quanto ao nível de escolaridade dos informantes, também apresentou percentuais muito próximos: o futuro do pretérito tem frequência de $65,5 \%$ para falantes com nível superior de escolaridade e $69 \%$ para falantes com o nível médio, conforme os dados da tabela 06.

Tabela 06: atuação do grupo de fatores escolaridade do informante

\begin{tabular}{|c|c|c|}
\hline Variantes & Futuro do pretérito & $\begin{array}{l}\text { Pretérito } \\
\text { imperfeito }\end{array}$ \\
\hline Escolaridade & $\begin{array}{l}\text { (n }{ }^{\circ} \text { de ocor./total)/ } \\
\text { perc. }\end{array}$ & $\begin{array}{l}\left(\mathrm{n}^{\circ} \text { de ocor./total }\right) / \\
\text { perc. }\end{array}$ \\
\hline Ensino médio & $(40 / 58) / 69 \%$ & $(18 / 58) / 31 \%$ \\
\hline Ensino superior & $(36 / 55) 65,5 \%$ & $(19 / 55) 34,5 \%$ \\
\hline
\end{tabular}

Fonte: elaborada pelos pesquisadores.

Ainda que os percentuais sejam muito próximos, os resultados obtidos não confirmaram nossa hipótese, uma vez que a forma conservadora, o futuro do pretérito, teve maior frequência na fala de informantes com ensino médio e a forma inovadora, o pretérito imperfeito, maior frequência na fala de informantes com ensino superior. Esses dados diferem dos obtidos por Brito 
(2018), que mostram que a forma prestigiada é favorecida por informantes com ensino superior e o pretérito imperfeito por informantes com ensino fundamental e médio.

\section{f) ordem estrutural da prótase}

A relação entre a prótase (oração condicionante) e a apódose (oração condicionada) pode apresentar-se em estrutura condicional de ordem linear canônica (prótase + apódose) ou em construção condicional de ordem inversa (apódose + prótase), em que a apódose configura-se como a consequência ou resultado da resolução da condição enunciada na prótase, conforme Neves (2000). A ordem canônica ou ordem natural tende a ser a mais frequente e consequentemente a estrutura não marcada em língua portuguesa (GIVON,1991), uma vez que é natural que se apresente, primeiramente, as condições necessárias (prótase) para que determinado fato (apódose) se realize, isto é, a interpretação do estado de coisas da apódose depende exclusivamente da prótase, um raciocínio lógico-semântico em dada duas proposições p e q verdadeiras, temos “se p, então q" (NEVES, 2000; BRITO, 2014).

A distribuição das variantes quanto à ordem estrutural da prótase apresenta percentuais muito próximos, 67,3\% e 66,7\%, respectivamente para o futuro do pretérito e $32,7 \%$ e $33,3 \%$ para o pretérito imperfeito nos dados desta pesquisa, conforme a tabela 07.

Tabela 07: atuação do grupo de fatores ordem da conjunção

\begin{tabular}{l|l|l}
\hline Variantes & Futuro do pretérito & Pretérito imperfeito \\
\hline $\begin{array}{l}\text { Ordem estrutural da } \\
\text { prótase }\end{array}$ & $\begin{array}{l}\left(\mathbf{n}^{\mathbf{o}} \text { de ocor./total)/ }\right. \\
\text { perc. }\end{array}$ & $\begin{array}{l}\left.\mathbf{( n}^{\mathbf{o}} \text { de ocor./total }\right) / \\
\text { perc. }\end{array}$ \\
\hline $\begin{array}{l}\text { Ordem canônica: } \\
\text { prótase + apódose }\end{array}$ & $(66 / 98) / 67,3 \%$ & $(32 / 98) / 32,7 \%$ \\
\hline $\begin{array}{l}\text { Ordem inversa: } \\
\text { apódose + prótase }\end{array}$ & $(10 / 15) / 66,7 \%$ & $(5 / 15) 33,3 \%$ \\
\hline
\end{tabular}

Fonte: elaborada pelos pesquisadores.

Os dados sugerem que a ordem estrutural da prótase não tem relevância sobre a escolha de uma ou outra variante, diferentemente dos resultados encontrados por Dias (2007), cujos dados sugerem o pretérito imperfeito sofre influência da ordem icônica e o futuro do pretérito é influenciado pela ordem não icônica.

As ocorrências (6) e (7), respectivamente, a ordem canônica e a ordem inversa exemplificam o futuro do pretérito e as ocorrências (8) e (9), respectivamente, exemplificam o pretérito imperfeito.

(6) Se ele tivesse um bom comportamento ele não estaria lá. 
(7) ele não faria isso de maneira nenhuma não faria se ele tivesse longe o sentimento dele.

(8) se existisse responsabilidade você ia pensar duas vezes antes de praticar e ter um filho

(9) ai era o fim fazia tudo que ela queria se ela me garantisse esse horário.

Para Givón, forma e função se relacionam, diferentemente do postulado estruturalista de arbitrariedade do signo linguístico, já que devemos entender a iconicidade como motivação. O próprio Givón (1984) considera que certas expressões linguísticas, quando motivadas, têm a capacidade de se modificarem, devido, certamente, a pressões do uso. Segundo Dias (2007), os princípios de quantidade, de proximidade e de ordem sequencial influenciam na disposição de constituintes no discurso, já que a quantidade de informação a ser codificada juntamente com a proximidade cognitiva dos constituintes linguísticos norteia a construção do sentido. E é a partir disto que a ordem e os elementos da estrutura linguística se harmonizam, no momento da interação entre os interlocutores, quando o falante é motivado a falar aquilo que julga mais importante para seu ouvinte.

\section{g) polaridade da construção condicional}

No que concerne à polaridade da construção condicional, os dados revelam que, tanto para o futuro do pretérito quanto para o imperfeito, os percentuais da polaridade afirmativa e negativa são praticamente idênticos, ao que se pode afirmar que não há relação entre polaridade e estruturação da condicionalidade em língua portuguesa.

Tabela 08: atuação do grupo de fatores polaridade

\begin{tabular}{l|l|l}
\hline Variantes & Futuro do pretérito & Pretérito imperfeito \\
\hline Polaridade & $\begin{array}{l}\mathbf{( n}^{\mathbf{o}} \text { de ocor./total)/ } \\
\text { perc. }\end{array}$ & $\begin{array}{l}\mathbf{( n}^{\mathbf{o}} \text { de ocor./total)/ } \\
\text { perc. }\end{array}$ \\
\hline Afirmativa & $(63 / 94) / 67 \%$ & $(31 / 94) 33 \%$ \\
\hline Negativa & $(13 / 19) / 68,4 \%$ & $(6 / 19) / 31,6 \%$ \\
\hline
\end{tabular}

Fonte: elaborada pelos pesquisadores.

Sendo a polaridade importante recurso para veicular informações lógico-semânticas e semântico-discursivas (NEVES, 2006), esperávamos que as variantes investigadas nesta pesquisa fossem sensíveis à polaridade, mas, pelos dados de nossa pesquisa, não apresentaram relevância estatística e nem relevância em termos de frequência, tendo sido os percentuais de ambas as variantes muito próximos tanto para a polaridade positiva, quanto a polaridade 
negativa. Caberia, em outra oportunidade, investigar o alcance da negação (BUBLITZ, 1992), isto é, a posição do elemento negativo na construção condicional (prótese ou apódose), para verificar se o escopo de atuação do morfema negativo influencia a especialização entre as variantes investigadas.

\section{h) fluxo de informação}

Reconhecendo a oração como uma unidade informacional, de natureza comunicativa, procuramos observar a alternância entre futuro do pretérito e pretérito imperfeito em construções contrafactuais no que diz respeito à organização do fluxo de informação (dado ou novo) na estruturação dessas construções. Os resultados mostram que a variante futuro do pretérito teve percentual de $86,7 \%$, quando se trata de informação dada e $64,3 \%$ quando está associada a uma informação nova. Já a variante pretérito imperfeito apresentou frequência de uso de 13,3\% ligada à informação dada e 35,7\% à informação nova. Vejamos os dados na tabela a seguir:

Tabela 09: atuação do grupo de fatores fluxo de informação

\begin{tabular}{l|l|l}
\hline Variantes & Futuro do pretérito & Pretérito imperfeito \\
\hline $\begin{array}{l}\text { Fluxo de } \\
\text { informação }\end{array}$ & $\begin{array}{l}\mathbf{( n}^{\mathbf{0}} \text { de ocor./total)/ } \\
\text { perc. }\end{array}$ & $\begin{array}{l}\text { (n' de ocor./total)/ } \\
\text { perc. }\end{array}$ \\
\hline Dado & $(13 / 15) / 86,7 \%$ & $(2 / 15) 13,3 \%$ \\
\hline Novo & $(63 / 98) / 64,3 \%$ & $(35 / 98) 35,7 \%$
\end{tabular}

Fonte: elaborada pelos pesquisadores.

Pelos dados de nossa pesquisa, ainda que não se possa falar em relevância estatística, uma vez que o grupo de fatores não foi selecionado como estatisticamente relevante pelo Goldvarb-X, a informação dada parece favorecer a variante conservadora, em termos de frequência, com diferenças percentuais bastante relevantes, ao passo que a informação nova parece beneficiar a variante inovadora. Para Chafe (1976), dado é o conhecimento que o falante assume estar na consciência do ouvinte no momento da interação. Novo ou informação nova tem relação com a informação que o falante acredita está acrescentando à consciência do ouvinte quanto estabelece uma interação comunicativa.

Nesse sentido, a relação entre futuro do pretérito e dadidade pode evidenciar uma preferência no empacotamento da oração enquanto mensagem na construção de efeitos de contrafactualidade, tal como ilustrado na ocorrência (10) adiante:

(10) Em relação a Fortaleza se ela é assim bem planejada eu acho que ela deveria ser ter uma estrutura melhor né a estrutura dela não é muito boa deveria ter uma estrutura melhor 
A ocorrência (10), acima, revela um "emparelhamento" entre o nível morfossintático, da estrutura não marcada, preferida na expressão da contrafactualidade (cognitivamente mais saliente), e o nível contextual da oração, ligado à "informação velha", menos marcada do ponto de vista da relevância comunicativa, já que funciona como "pano de fundo", para a introdução de informações novas - princípio de iconicidade.

\section{Considerações finais}

Nesta pesquisa, realizamos uma análise sociofuncionalista da variação entre as formas de pretérito imperfeito e futuro do pretérito em construções condicionais em dados de fala de informantes de Fortaleza, coletados por meio de entrevistas sociolinguísticas. Os dados foram submetidos ao programa Goldvarb X, testada a influência de grupos de fatores linguísticos e extralinguísticos. Os resultados apontam uma preferência pelo uso da variante canônica, conservadora, o futuro do pretérito, com frequência de $67,3 \%$ dos dados.

Foram selecionados como estaticamente relevantes os grupos de fatores complexidade estrutural, modalidade e sexo, nesta ordem. No que diz respeito à complexidade estrutural, o futuro do pretérito foi favorecido pela forma simples, enquanto a perífrase condiciona a variante pretérito imperfeito. Esse resultado alinha-se ao de Dias (2007) e tem relação com o subprincípio da quantidade (GIVÓN, 1992), do princípio de iconicidade, que prevê uma correlação entre quantidade de informação e codificação na estrutura linguística, ou seja, o pretérito imperfeito, na função de futuro do pretérito para expressar contrafactualidade, codifica-se, preferencialmente, por meio da forma verbal perifrástica (verbo auxiliar ir no imperfeito + verbo no infinitivo), para especificar a expressão da futuridade em relação ao tempo passado e da contrafactualidade no que diz respeito à ocorrência do estado de coisa descrito na proposição.

Em relação ao grupo de fatores modalidade, a análise revela uma relação motivada entre a modalidade deôntica e o futuro do pretérito em construções contrafactuais. Esse dado, de certo modo, já era esperado, uma vez que declarações deônticas não se ligam à descrição de estados de mundo, mas a "obrigações" que se caracterizam por uma referência ao futuro, como consequência de um "elemento de desejo" (JESPERSEN, 1924 apud NEVES, 2006, p. 189).

Os resultados também apontam para o condicionamento da variante futuro do pretérito, considerada a canônica na tradição gramatical, por informantes do sexo feminino, cuja frequência do uso foi de $75,5 \%$ no corpus analisado, na mesma direção dos resultados encontrados por Oliveira (2010), e confirmando a hipótese clássica da sociolinguística de que as mulheres tendem a favorecer a forma de prestígio (PAIVA, 2007). 
A relevância de condicionadores sociais (sexo) e linguísticos (modalidade e complexidade estrutural) na variação entre o futuro do pretérito e pretérito imperfeito em construções condicionais contrafactuais, esses últimos inspirados no paradigma funcionalista, sob a configuração teórica do sociofuncionalismo, se coaduna com os pressupostos de que a linguagem não é um fenômeno isolado e de que a língua não pode ser descrita como um sistema autônomo, homogêneo, desvinculado do uso. No cerne desses postulados, acomoda-se a concepção de gramática decorrente do equilíbrio de forças externas e de forças internas ao sistema linguístico, conforme Du Bois (1985), que o leva a afirmar que a gramática é sensível às pressões do uso.

O sistema linguístico é heterogêneo, resultado da heterogeneidade da estrutura social, havendo, portanto, há uma relação entre a estrutura social da comunidade de fala, heterogênea por excelência, e a estrutura variável do sistema linguístico, que pode ser sistematizada a partir da verificação do sistema social. Por ser heterogêneo e sofrer processos de variação e mudança, a natureza do sistema linguístico não é estanque, mas permite que inovações provenientes dos diversos usos que os falantes fazem das expressões linguísticas se materializem na estrutura da língua, de modo que uma determinada forma pode ser usada em outros contextos e assumir novas funções, iniciando processos de variação que podem culminar em mudança, o que justifica uma abordagem sociofuncionalista, como a que empreendemos nesta pesquisa.

\section{REFERÊNCIAS}

AMORIM, V. R. S.; SOUSA, V. V. Convergências e Divergências Epistemológicas no Hibridismo entre a Sociolinguística e o Funcionalismo. Id on Line Rev.Mult. Psic., vol.13, n.44, 2019.

BARBOSA, T. A. M. A variação entre futuro do pretérito e pretérito imperfeito do indicativo em orações condicionais iniciadas por "SE" na fala uberlandense. Dissertação (Mestrado em Linguística) - Universidade Federal de Uberlândia, Uberlândia, 2005.

BRITO, N. J. A. A expressão do condicionado contrafactual em construções se p, então q no português brasileiro. 2014. 113 f. Dissertação (Mestrado em Linguística Aplicada; Literatura Comparada) - Universidade Federal do Rio Grande do Norte, Natal, 2014.

Alternância entre futuro do pretérito e pretérito imperfeito do indicativo no domínio funcional da condição contrafactual em comentários no facebook. 2018. 132f. Tese (Doutorado em Estudos da Linguagem) - Centro de Ciências Humanas, Letras e Artes, Universidade Federal do Rio Grande do Norte, Natal, 2018. 
BECHARA, E. Moderna Gramática Portuguesa. 37 ed. revista e amp. Rio de Janeiro, Lucerna, 2003.

BORBA, F. da S. Uma gramática de valências para o português. São Paulo: Ática, 1996.

BUBLITZ, W. Transferred negation and modality. Journal fo Pragmatics. V.18, 1992.

Chafe, W. L. Givenness, contrastiveness, definiteness, subjects, and point of view. In: Li, C. (ed.). Subject ant Topic. New York. Academic Press, 1976, p. 25-55.

CORACINI, M. J. Um fazer persuasivo: o discurso subjetivo da ciência. São Paulo: Pontes - Educ, 1991.

CUNHA, Celso; CINTRA, Luís Filipe Lindley. Nova Gramática do português Contemporâneo. 7 ed. Rio de Janeiro, Lexicon, 2017.

DIAS, F. M. P de C. Variação e funcionalidade modo-temporal no português oral de fortaleza/ce: futuro do pretérito versus pretérito imperfeito na codificação da eventualidade em construções condicionais. (2007). Dissertação (Mestrado em Linguística). Programa de Pós-graduação em Linguística, Universidade Federal do Ceará, Fortaleza.

A multifuncionalidade do futuro do pretérito nos séculos XVIII, XIX e XX: uma análise (socio)funcionalistaem revistas históricas do Instituto do Ceará. (2012) Tese (Doutorado em Linguística). Programa de Pós-graduação em Linguística, Universidade Federal do Ceará, Fortaleza.

DUBOIS, J. Competing Motivations. In: HAIMAN, John (org.). Typological Studies in Language. Amsterdam: John Benjamins Publishing Company, 1984. (p. 229-240).

GIVÓN, T. Markeness in Grammar: distributional, communicative and cognitive correlates of syntactic structure. Technical Report, No 90/8, University of Oregon, 1990. 1991a.

Functionalism and grammar: a prospectus. University of Oregon,

Isomorphism in the Grammatical Code: cognitive and biological considerations. Studies in language. 1992.

GÖRSKI, E. M.; COELHO, I. L. Variação linguística e ensino de gramática.Work. pap. linguíst., v. 10, n. 1, p. 73-91, Florianópolis, jan. jun., 2009.

HALLIDAY, M. A. K. An Introduction to functional grammar. London: Edward Arnold Publishers, 1985. 
Spoken and written language. Oxford: University Press, 1989.

An introduction to functional Grammar. 3. Ed. London: Hodder Education, 2004.

LABOV, W. Padrões sociolingüísticos. Tradução de M. Bagno; M. M. P. Scherre; C. R. Cardoso. São Paulo: Parábola Editorial, 2008 [1972].

MAY, G. H. Discutindo o papel do funcional no sociofuncionalismo. Work. pap. linguíst., v. 10, n. 2, Florianópolis, 2009.

MENEZES, L. C. Expressões linguísticas modalizadoras deônticas em função argumentativa: um exercício de análise retórico-funcional. 2011. 334f. - Tese (Doutorado) - Universidade Federal do Ceará, Departamento de Letras Vernáculas, Programa de Pós-graduação em Linguística, Fortaleza (CE), 2011.

NARO, A. J. "Modelos quantitativos e tratamento estatístico". In: Mollica (org.), Introdução à Sociolinguística Variacionista. Rio de Janeiro, UFRJ, 1992.

NEVES, M. H. M. Estudos funcionalistas no Brasil. D.E.L.T.A., São Paulo, v.15, n. esp., p. 71-104. 1999.

. Texto e Gramática. São Paulo: Contexto, 2006.

OLIVEIRA, F. A. de L. A alternância entre o futuro do pretérito e o pretérito imperfeito do indicativo na oração principal em contextos hipotéticos na fala de alagoanos. 2010. 128 f. Dissertação (Mestrado em Linguística; Literatura Brasileira) - Universidade Federal de Alagoas, Maceió, 2010.

PAIVA, M. C. A variável gênero/sexo. In: MOLLICA, M. C.; BRAGA, M. L. Introdução à Sociolinguística: o tratamento da variação. São Paulo: Contexto, 2007.

PIRES DE OLIVEIRA, R. Uma história de delimitações teóricas: 30 anos de semântica no Brasil. D.E.L.T.A., vol. 15, n. especial, 1999.

SANKOFF, D.; TAGLIAMONTE, S.; SMITH, E. Goldvarb X: a variable rule application for Macintosh and Windows. Department of Linguistics, University of Toronto/Department of Mathematics, University of Ottawa, 2005.

SILVA, C. R.; OLIVEIRA, M. J. Variação/mudança numa perspectiva sociofuncionalista. Miguilim - Revista Eletrônica do Netlli, Crato, v. 6, n. 2, p. 243-264, maio-ago. 2017.

TAVARES, M. A. A gramaticalização de E, AÍ, DAÍ, e ENTÃo: estratificação e mudança no domínio funcional da sequenciação retroativopropulsoradeinformações - um estudo sociofuncionalista. 2003. Tese 
(Doutorado em Linguística) Curso de Pós-graduaçãoem Linguística, Universidade Federal deSanta Catarina, Florianópolis.

Sociofuncionalismo: um duplo olhar sobre a variação e a mudança linguística. Edição especial Abralin/SE. Itabaiana, Ano VIII, v.17, jan./jun. 2013.

; GÖRSKI, E. M. reflexões teórico-metodológicas a respeito de uma interface sociofuncionalista. Natal RN, revista do GELNE, v. 15, número especial, 2013.

TORRES, F. F. O gerúndio na expressão de tempo futuro: um estudo sociofuncionalista. 2009 Dissertação (Mestrado em Linguística) - Programa de Pós-graduação em Linguística, Universidade Federal Ceará, Fortaleza.

Recebido em 12 de agosto de 2021

Aceito em 8 de outubro de 2021. Publicado em 30 de dezembro de 2021.

\section{SOBRE OS AUTORES}

Fábio Fernandes Torres é mestre e doutor em Linguística pela Universidade Federal do Ceará (UFC), Professor do Curso de Letras - Língua Portuguesa e do Programa de Pós-Graduação em Estudos da Linguagem (PPGLin), Líder do Grupo de Estudos e Pesquisas Sociolinguísticas das Variedades Lusófonas - SOCIOLUSO e Pesquisador do Grupo de Estudos em Linguística Funcional - GELF, na Universidade da Integração Internacional da Lusofonia Afro-Brasileira - Unilab. Também é pesquisador do Grupo de Pesquisas Sociolinguísticas do Ceará - SOCIOLIN-CE e do Grupo de Estudos Funcionalistas GEF, da UFC. Tem experiência na área de Linguística, com ênfase no Funcionalismo e na Sociolinguística, atuando principalmente nos seguintes temas: variação e mudança linguísticas, gerúndio, tempo, aspecto e modalidade.

\section{Izabel Larissa Lucena Silva}

Graduada em Letras - Português/Italiano, mestra e doutora pela Universidade Federal do Ceará. (UFC). Foi bolsista da Capes e desenvolveu doutorado sanduíche no Instituto de Linguística Computacional, sob a orientação do Prof. Dr. John Lachlan Mackenzie. É professora do Curso de Letras - Língua Portuguesa e do Programa de Pós-Graduação em Estudos da Linguagem (PPGLin), líder do Grupo de Estudos em Linguística Funcional - GELF, na Universidade da Integração 
Internacional da Lusofonia Afro-Brasileira - Unilab. Também é pesquisadora do Grupo de Estudos Funcionalistas - GEF, da UFC. Tem experiência em descrição e análise linguística, com ênfase na relação entre gramática, cognição e discurso. 